\title{
Modelling Based Analysis and Optimization of Simultaneous Saccharification and Fermentation for the Production of Lignocellulosic-Based Xylitol
}

Ibnu Maulana Hidayatullah

Dept. of Chemical Engineering, Institut Teknologi Bandung

Tjandra Setiadi

Dept. of Chemical Engineering, Insititut Teknologi Bandung

Made Tri Ari Penia Kresnowati ( $\nabla$ kresnowati@che.itb.ac.id)

Institut Teknologi Bandung https://orcid.org/0000-0002-8079-4677

\section{Research}

Keywords: lignocellulose, modelling, simultaneous saccharification and fermentation, xylitol

Posted Date: May 11th, 2021

DOl: https://doi.org/10.21203/rs.3.rs-497052/v1

License: (c) (i) This work is licensed under a Creative Commons Attribution 4.0 International License.

Read Full License 


\section{Modelling Based Analysis and Optimization of Simultaneous}

\section{Saccharification and Fermentation for the Production of}

\section{$3 \quad$ Lignocellulosic-Based Xylitol}

I.M. Hidayatullah ${ }^{1}(0000-0003-4412-2547)$, T. Setiadi ${ }^{1}(0000-0003-1850-4680)$, and M.T.A.P. Kresnowati ${ }^{1,2}$ (0000-0002-8079-4677)

${ }^{1}$ Department of Chemical Engineering, Faculty of Industrial Technology, Institut Teknologi Bandung, Jalan Ganesha No. 10, Bandung, West Java, Indonesia, 40132

${ }^{2}$ Department of Food Engineering, Faculty of Industrial Technology, Institut Teknologi Bandung, Kampus Jatinangor, Sumedang, Indonesia

\section{Corresponding Author: M.T.A.P. Kresnowati (kresnowati@che.itb.ac.id)}

Abstract.

Simultaneous saccharification and fermentation (SSF) configuration offers an efficient used of the reactor. In this configuration, both the hydrolysis and fermentation processes are conducted simultaneously in a single bioreactor and the overall process may be accelerated. Problems may arise if both processes have different optimum conditions, and therefore process optimization is required. This paper presents the development of mathematical model over SSF strategy implementation for producing xylitol from hemicellulose component of lignocellulosic materials. The model comprises of the hydrolysis of hemicellulose and the fermentation of hydrolysate into xylitol. The model was simulated for various process temperature, prior hydrolysis time, and inoculum concentration. Simulation of the developed kinetics model shows that the optimum SSF temperature is $36^{\circ} \mathrm{C}$, whereas conducting a prior hydrolysis at its optimum hydrolysis temperature will further shorten the processing time and increase the xylitol productivity. On the other hand, increasing the inoculum size will shorten the processing time further. For an initial xylan concentration of $100 \mathrm{~g} / \mathrm{L}$, the best condition is obtained by performing 21-hour prior hydrolysis at $60^{\circ} \mathrm{C}$, followed by SSF at $36^{\circ} \mathrm{C}$ by adding $2.0 \mathrm{~g} / \mathrm{L}$ inoculum, giving $46.27 \mathrm{~g} / \mathrm{L}$ xylitol within 77 hours of total processing time. 
2 Xylitol is a pentitol or polyalcohol sugar $\left(\mathrm{C}_{5} \mathrm{H}_{12} \mathrm{O}_{5}\right)$ commonly used in the pharmaceutical sector as a dental remineralizing agent. Xylitol can increase salivation and inhibit the cellular activity of cariogenic organisms, thus reducing plaque, gum swelling, dental erosion, and preventing xerostomia (lack of saliva production) [1-5].

5 Xylitol can be used as a sweeter; it is commonly used in food industries and is categorized as safe for diabetics

6 [6-9]. Other than that, xylitol is used as a building block for ethylene glycol and propylene glycol formation using

7 Ruthenium or copper as the catalyst in hydrogenolysis process $[10,11]$ and as a building block for $2,3,4,5$ tetrahydroxypentanoic acid and xylonic acid using diperiodatoargentate (III) and Ru (III) as the catalyst through oxidation $[12,13]$.

Conventionally, xylitol production involves hydrogenation of xylose from lignocellulosic biomass.

11 Lignocellulose-based materials are pretreated and hydrolyzed using dilute sulfuric acid, after which the hydrolyzate is purified using chromatography to obtain xylose. Pure xylose solution is then catalytically hydrogenated using Raney-Nickel or Ru/C (Ruthenium-carbon) as the catalysts so that it becomes xylitol $[14,15]$. This conventional xylitol production method has several disadvantages: the process uses a lot of energy as it is conducted at relatively high pressure and temperature $\left(50-60\right.$ bar and $\left.140-200^{\circ} \mathrm{C}\right)$; the process requires delicate purification of the hydrolysate to obtain pure xylose; and need more investment in types of equipment, considerable intermediate purification, product recovery, catalyst deactivation, and recycling process [15-17]. An alternative method of producing xylitol from lignocellulose-based materials involves a bioprocessing system that includes enzymatic hydrolysis using xylanase to obtain xylose containing hydrolysate, and microbial fermentation to convert xylose in hydrolysate into xylitol $[16,18,19]$. The hydrolysis and fermentation processes are normally conducted in different reactors or better known as separate hydrolysis and fermentation (SHF) because they have different operating conditions. As a result, the fermentative sugar production process requires a long processing time and is still considered uneconomical. Alternatively, the bioprocess route for xylitol production, that is the hydrolysis and the fermentation, can be conducted simultaneously or better known as simultaneous saccharification and fermentation (SSF). In principle, both the hydrolysis and fermentation processes take place simultaneously in the same reactor, providing direct utilization of hydrolysis product, that is the monomeric sugar, as the carbon source for the fermenting agentform the desired product [19-21]. Consequently, both processes are conducted at the same operating condition. Moreover, the application SSF process from lignocellulose-based materials minimizes the potential substrate 
inhibition on the fermentation process as well as the potential product inhibition on the enzymatic hydrolysis process, increases the yield and productivity [21-23].

Previous studies showed that the use of SSF combined with prior hydrolysis in ethanol production was able to increase the ethanol yield than the SSF only [24, 25]. Burhan et al. [19] reported the implementation of SSF for xylitol production from oil palm empty fruit bunch (OPEFB). In his research, the duration of the prior hydrolysis process was varied to achieve the optimum results. Overall, at the same total processing time, up to 4-fold increase of the xylitol yield from OPEFB when compared with that of SHF was obtained [19]. Prior hydrolysis is necessary to provide sufficient substrate for initializing the fermentation. However, the optimum temperature for conducting both hydrolysis and fermentation simultaneously has been overlooked, the SSF was conducted at the optimum fermentation temperature that led to low enzymatic-hydrolysis activity. The optimum temperature of xylan hydrolysis using xylanase is reported in the range of $40-70^{\circ} \mathrm{C}[26,27]$, whereas the optimum temperature for xylitol-producing yeast fermentation is reported in the range of $10-44^{\circ} \mathrm{C}$ [28-31]. Conducting the SSF at the optimum temperature for both hydrolysis and fermentation would significantly increase the process performance. Followingly the temperature setting for SSF as well as the duration of the prior hydrolysis process can be optimized further to higher xylitol productivity.

Modelling may serve as a useful tool to explore the interaction of between parameters. In particular kinetic modelling can be applied to search for the optimal SSF configuration, that is the operating temperature, the duration of the prior hydrolysis or the initialization of the fermentation based on certain initial cell concentration. This paper presents the development of a kinetic model for lignocellulosic material-based xylitol production using SSF. The model was further used for thoroughly studying the effect of process temperature, prior hydrolysis and switching time (the start of SSF) as well as the inoculum size to estimate xylitol concentration and its productivity so that the results could feasibly be applied on a laboratory level and eventually developed on both a pilot and an industrial-scale.

\section{Methodology}

The model was built by assuming that the process took place in a single batch reactor. The xylan-based hemicellulose in lignocellulosic material was pretreated before being put into the reactor for enzymatic hydrolysis and fermentation. Xylitol production through the bioprocessing pathway is shown in Fig 1. During the hydrolysis process, xylan was hydrolysed into xylose. During the fermentation process, xylose was further utilized by the 
yeast as the carbon sources for biomass growth and xylitol formation. In this model it was assumed that xylitol was the only metabolite product that was produced during the fermentation and that a decrease in cell concentration was neglected. Overall, the mass balances describing the process are presented in Eq. $1-4$.

$$
\begin{gathered}
\frac{d C_{x y l a n}}{d t}=-r_{\text {hyd }} \\
\frac{d C_{x y l o s e}}{d t}=1.14 \times r_{\text {hyd }} Y_{C_{x y l o s e} / C_{x y l a n}}-r_{\text {biomass }} \frac{1}{Y_{X / C_{x y l o s e}}} \\
\frac{d C_{X}}{d t}=r_{\text {biomass }} \\
\frac{d C_{X y l i t o l}}{d t}=r_{x y l i t o l}
\end{gathered}
$$

4

\section{$5 \quad$ Kinetic Model Developments}

\section{$6 \quad$ Xylan hydrolysis}

7 The rate of hydrolysis process $\left(r_{h y d}\right)$ was modelled using the Michaelis Menten reaction kinetics equation as 8 presented in Eq. 5, with $r_{\text {max,hyd }}$ (g/(L.h)) is the maximum rate of hydrolysis, $C_{x y l a n}$ is the concentration of xylan $9(\mathrm{~g} / \mathrm{L})$, and $K_{m, h y d}$ is the Michaelis constant for the xylan hydrolysis $(\mathrm{g} / \mathrm{L})[13]$.

$$
r_{\text {hyd }}=\frac{r_{\text {max }, \text { hyd }} \times C_{x y l a n}}{K_{\text {m,hyd }}+C_{x y l a n}}
$$

Like other chemical reactions, a higher temperature can increase the rate of enzymatic reactions. However, higher temperature also raises the rate of thermal denaturation and the loss of the biocatalyst activity [32, 33]. Within the range of $40-60^{\circ} \mathrm{C}$, however, the overall rate of xylan hydrolysis using xylanase is still increasing with temperature

13 [26] and the overall effect of temperature on this enzymatic reaction can be modelled following the Arrhenius equation as is presented in Eq. 7.

$$
\begin{gathered}
r_{\text {max }, \text { hyd }}=k_{\text {hyd }} \times E_{0} \\
k_{\text {hyd }}=A_{\text {hyd }} \times e^{-\frac{E_{a, h y d}}{R T_{h y d}}}
\end{gathered}
$$

$15 E_{0}$ is the concentration of the initial concentration of enzyme used $(\mathrm{g} / \mathrm{L}), k_{h y d}$ is the catalytic constant of hydrolysis $\left(h^{-1}\right), A_{h y d}$ is the Arrhenius constant for the hydrolysis reaction $\left(h^{-1}\right), E_{a, h y d}$ is the activation energy of the hydrolysis reaction $(\mathrm{kJ} / \mathrm{mol}), R$ is the universal gas constant $(\mathrm{kJ} / \mathrm{mol} . \mathrm{K})$, and $T_{\text {hyd }}$ is the temperature of hydrolysis (K). 
2 The rate of biomass growth is defined following the first order reaction kinetics with respect to the biomass 3 concentration $\left(C_{X}, \mathrm{~g} / \mathrm{L}\right)($ Eq. 8$)$, whereas the biomass specific growth rate $\left(\mu, h^{-1}\right)$ is defined following the Monod 4 equation that correlates the the specific growth rate with substrate (xylose) concentration $\left(C_{x y l o s e}, \mathrm{~g} / \mathrm{L}\right)$.

$$
\begin{gathered}
r_{\text {biomass }}=\mu \times C_{X} \\
\mu=\frac{\mu_{\text {max }, \text { fer }} \times C_{x y l o s e}}{K_{s, f e r}+C_{x y l o s e}}
\end{gathered}
$$

5 In which $K_{s, f e r}$ is the growth saturation constant on xylose $(\mathrm{g} / \mathrm{L})$ and $\mu_{\text {max } \text { fer }}$ is the maximum specific growth

6 rate of the fermentation process $\left(h^{-1}\right)$. Further, the effect of temperature of biomass growth can be modelled 7 following Sanchéz et al. [29] as:

$$
\mu_{\text {max }, \text { fer }}=A_{\text {fer }} \times e^{-\frac{E_{g, f e r}}{R T}}-B_{\text {fer }} \times e^{-\frac{E_{d, f e r}}{R T}}
$$

8 Where $E_{g, f e r}$ is the cell activation energy for growth $(\mathrm{kJ} / \mathrm{mol}), E_{d, f e r}$ is the deactivation energy when the cell has 9 entered the death phase $(\mathrm{kJ} / \mathrm{mol}), A_{\text {fer }}$ is the cell activation coefficient $\left(h^{-1}\right), B_{f e r}$ is the cell inactivation 10 coefficient $\left(h^{-1}\right)$. Other effects of microenvironment conditions, such as the oxygen concentration in the 11 fermentation broth or the acidity level of the media, were not considered in this model. Combination of equations 12 (8), (9), and (10) are given as follows:

$$
r_{\text {biomass }}=\left(\frac{\left(A_{\text {fer }} \times e^{-\frac{E_{g, f e r}}{R T}}-B_{\text {fer }} \times e^{-\frac{E_{d, f e r}}{R T}}\right) \times C_{x y l o s e}}{K_{s, f e r}+C_{x y l o s e}}\right) \times C_{X}
$$

\section{Xylitol formation}

Xylitol production rate is modelled using the growth-associated product. The equation is approached as follows [32]:

$$
r_{x y l i t o l}=\mu \times C_{X} \times Y_{C_{x y l i t o l} / X}
$$

Combination of equations (9), (10), and (12) are given as follows.

$$
r_{x y l i t o l}=\left(\frac{\left(A \times e^{-\frac{E_{g}}{R T}}-B \times e^{-\frac{E_{d}}{R T}}\right) \times C_{x y l o s e}}{K_{s}+C_{x y l o s e}}\right) \times C_{X} \times Y_{C_{x y l i t o l} / X}
$$

Where $Y_{C_{x y l i t o l} / X}$ is the yield of xylitol formed from biomass activity. 


\section{Determination of cell and xylitol productivity}

2 After the xylose was completely converted, we could measure how much cell and xylitol productivity obtained in 3 each configuration process. The cell productivity is determined as follows (Eq. 14).

$$
Q_{X}=\frac{C_{X}}{t_{p}}
$$

4 Where $Q_{X}$ and $t_{p}$ are cell productivity (g/(L.h)) and total processing time (h), respectively. Also, xylitol 5 productivity is defined as follows:

$$
Q_{x y l i t o l}=\frac{C_{x y l i t o l}}{t_{p}}
$$

6 Where $Q_{X}$ is the xylitol productivity (g/(L.h)).

7

\section{Model Simulation and Boundary Condition}

9 The simulation started with the hydrolysis of xylan to xylose followed by the fermentation of the xylose to xylitol.

10 The initial concentration of xylan was set at $100 \mathrm{~g} / \mathrm{L}$. Unless stated otherwise, the initial biomass concentration of

$110.5 \mathrm{~g} / \mathrm{L}$ was introduced at the beginning of the fermentation process. The maximal total process time was set to 12 be 200 hours.

13 All simulation processes were stopped when the xylitol reached the maximum concentration in each process and 14 the other compounds were considered not to interfere with the process. Particularly for Separate Hydrolysis and Fermentation (SHF), hydrolysis was halted if $1 \%$ of xylan residue was obtained. During hydrolysis, the xylobiose and other xylooligosaccharide formation were neglected. Moreover, the xylitol was assumed not consumed by cells or converted into the other compounds so that xylitol accumulation has decreased. The simulations were conducted using the Matlab R2018a. The supporting data for simulations are shown in Table 1. 


\section{$1 \quad$ Results and discussion}

\section{Mapping the effects of temperature on hydrolysis and fermentation}

3 Literature study indicated that the hydrolysis of xylan and the fermentation for xylitol production occured in

4 different temperature range. For example, Mardawati et al. [26] and Meilany et al. [27] reported the optimum temperature for xylan hydrolysis for obtaining the highest xylose yield at $60^{\circ} \mathrm{C}$, whereas Pappu and Gummadi [37] and Sánchez, et al. [29] reported the optimum temperature for fermentation at $35^{\circ} \mathrm{C}$. Indeed, previous study showed that the range temperature for the high biomass growth and xylitol productivity was $30-35^{\circ} \mathrm{C}[19,31,38]$. Burhan et al. [19] reported a decrease in fermentation xylitol performance when the temperature was increased from 30 to $37^{\circ} \mathrm{C}$. The mapping of the effects of temperature on hydrolysis and fermentation, in particular the maximum rate of hydrolysis $\left(\mathrm{k}_{\text {hyd }}\right)$ and the maximum specific growth rate of biomass $\left(\mu_{\max }\right)$, in the temperature range of $25-60^{\circ} \mathrm{C}$ are presented in Fig 2.

Within the temperature range of $25-60^{\circ} \mathrm{C}$, the xylan hydrolysis rate was shown to increase along with an increase in temperature, whereas three distinct trends of fermentation rate were observed. An increasing trend of the maximum specific biomass growth rate was observed between $25-34^{\circ} \mathrm{C}$. Between $34^{\circ} \mathrm{C}$ and $42^{\circ} \mathrm{C}$, a decreasing trend of the maximum specific biomass growth rate was observed. The biomass could not grow above $42^{\circ} \mathrm{C}$. The optimum condition for both hydrolysis and fermentation were expected to be in the range of $25-42^{\circ} \mathrm{C}$, in this condition both fermentation and hydrolysis can proceed, although not in each optimum condition.

\section{Separate hydrolysis-fermentation (SHF)}

Xylitol production via the SHF system was simulated as the reference. The SHF was conducted at the optimum temperature for each process, as have been calculated in the previous section (Fig 2). During this simulation, the hydrolysis was set to proceed at $60^{\circ} \mathrm{C}$ whereas the following fermentation was set to proceed at $34^{\circ} \mathrm{C}$. The temperature switch was assumed to occur instantly. Fermentation was initiated shortly after the completion of xylan hydrolysis, that was at $99 \%$ xylan conversion. The results of the simulation of xylitol production using the SHF method are shown in Fig 3.

Fig 3 shows that at 48 hours, 99\% of xylan has been converted, giving the xylose concentration of $112.68 \mathrm{~g} / \mathrm{L}$ and a residual xylan of $1.16 \mathrm{~g} / \mathrm{L}$. The fermentation was then initiated at that time and the simulation was continued until total processing time of 200 hours. Xylose was consumed slowly by the biomass for the first 32 hours of 
fermentation. At that time, the biomass was in the lag phase and xylitol was formed slowly. After 80 hours of processing time, fast decrease in xylose concentration was observed, indicating high consumption of xylose for growth and xylitol production. The final concentration of biomass and xylitol that were obtained in the simulation were $21.85 \mathrm{~g} / \mathrm{L}$ and $46.07 \mathrm{~g} / \mathrm{L}$, successively, which were achieved at the $6^{\text {th }}$ days or 128 hours of processing time. Dominguez et al. [38] reported that the xylitol production using $120 \mathrm{~g} / \mathrm{L}$ synthetic substrate by using $1.2 \mathrm{~g} / \mathrm{L}$ initial yeast concentration gave xylitol and yeast concentration near to $80 \mathrm{~g} / \mathrm{L}$ and $5 \mathrm{~g} / \mathrm{L}$, respectively, after 72-hour fermentation. The fermentation was conducted at the optimal fermentation temperature and all xylose were utilized within the observed fermentation time. This reported fermentation time was comparable to the time required for consuming all xylose in the fermentation simulation, 80 hours (Fig 3).

\section{Simultaneous saccharification and fermentation (SSF)}

During SSF, all components of the process: xylan as the substrate, the xylanolytic enzyme, and the biomass inoculum (as the fermenting agent) were present in the bioreactor, such that the hydrolysis and fermentation occured simultaneously. Two distinct strategies were evaluated: conducting SSF at the optimum hydrolysis temperature $\left(60^{\circ} \mathrm{C}\right)$ and conducting the SSF at the optimum fermentation temperature $\left(34^{\circ} \mathrm{C}\right)$. The simulation results are presented in Fig 4.

At the optimum hydrolysis temperature of $60^{\circ} \mathrm{C}(\mathbf{F i g} 4 \mathbf{a})$, xylan was converted into xylose resulting an increasing xylose profile until 48-hours. The following fermentation, however, could not proceed as the fermenting agent of xylitol production (such as Debaromyces hansenii, Debaromyces nepalensis, Pachysolen tannophilus, or Candida tropicalis) could only grow in the temperature range of $15-40^{\circ} \mathrm{C}[29-31,39,40]$. Thereby no biomass growth nor product formation is observed (Fig 2). By the end of this simulation, only as much as $115.31 \mathrm{~g} / \mathrm{L}$ of xylose was formed.

At the optimum fermentation temperature of $34^{\circ} \mathrm{C}(\mathbf{F i g} \mathbf{4 b})$, hydrolysis proceeded slowly. Xylan was slowly hydrolyzed and would be completely hydrolyzed at 110 hours. Although the biomass inoculum was already present from the start of SSF, the low xylose concentration led to slow biomass growth. Significant biomass concentration was only observed after 43 hours and the biomass reached stationary phase when the substrate exhausted. Xylose was completely utilized at 109 hours, resulting in xylitol and biomass concentration of 46.06 $\mathrm{g} / \mathrm{L}$ and $21.83 \mathrm{~g} / \mathrm{L}$, respectively. Nevertheless, in comparison to the SHF process, the SSF method proceeded faster to achieve the same xylitol concentration. Applying the fermentation optimum temperature is preferable than the optimum hydrolysis temperature in SSF. 
2 Simultaneous hydrolysis-fermentation at optimum SSF temperature

3 In determining the optimum temperature for SSF, simulations were conducted within the temperature range of $4 \quad 30-43^{\circ} \mathrm{C}$ using Eq. 7, Eq. 11, and Eq. 13 for temperature-dependent hydrolysis, biomass growth, and xylitol 5 formation, respectively. Fig 5 showed the contour plot between temperature, the processing time, and the resulting xylitol productivity. The lowest to the highest xylitol productivity was represented by the dark blue to dark red contour area, respectively.

The maximum xylitol concentration can always be achieved at various SSF temperature. However, the processing time required to achieve the maximum xylitol concentration varied with temperature, leading to a variation in the xylitol productivity. The low enzymatic activity at the range of temperature of $30-43^{\circ} \mathrm{C}$ resulted in slow xylose accumulation. The low xylose concentration led to slow biomass growth and xylitol formation. For total processing time under 60 hours, low xylitol productivity $(<0,15 \mathrm{~g} /(\mathrm{L} . \mathrm{h}))$ was observed at the simulated temperature range (Fig 5). An increasing trend of xylitol productivity was observed at processing time 60-100 hours. However, the xylitol productivity slowly decreased after 100 hours of processing time. The optimum xylitol productivity was achieved in the temperature range of $34-37^{\circ} \mathrm{C}$, marked by the dark red region in Fig 5. At $36^{\circ} \mathrm{C}$ the maximum xylitol concentration was achieved at 102 hours, gave the highest xylitol productivity of 0.45 g/(L.h). Conducting SSF at this optimum SSF temperature, $36^{\circ} \mathrm{C}$, led to higher xylitol productivity compared to conducting SSF at the optimum fermentation temperature.

Previous research on SSF for xylitol production from OPEFB that was conducted at $30^{\circ} \mathrm{C}$ with initial xylan concentration of $10 \mathrm{~g} / \mathrm{L}$ (assuming the average xylan composition in OPEFB was 22.5\% [41]) for 120 hours, gave xylitol productivity of $0.047 \mathrm{~g} / \mathrm{L}$ [19]. Compared to this, this ideal simulation showed faster processing time and resulted in higher xylitol productivity.

\section{Semi-simultaneous hydrolysis-fermentation and the effect of initial cell concentration}

The performance of SSF may be improved by conducting a prior hydrolysis process, at the optimized temperature for hydrolysis, before the initiation of SSF. The overall process, the combination of the prior hydrolysis process and the SSF process is called as semi-simultaneous hydrolysis and fermentation (semi-SSF). In practice the initiation of SSF can be set by the addition of biomass inoculum on various concentration. This event will be referred as the switching time, in the remaining discussion. 
1 The determination of the optimum switching time was conducted by varying the duration of prior hydrolysis,

2 ranging between 0 to 48 hours, at certain initial cell concentration. The results are shown in Fig 6, with the dark

3 blue to dark red colour denotes the lowest to highest xylitol concentration, respectively.

4 In general, an increase in the switching time resulted in longer total processing time required to achieve the 5 maximum xylitol concentration (Fig 6). The best configuration was obtained by prior hydrolysis time of 8 hours led to total processing time of 93 hours to achieve the maximum xylitol concentration (Fig $\mathbf{6 a}$ ). The later the switching time, the lower the ability of the biomass to ferment so that productivity decreases. The obtained results are consistent with previous study conducted by Burhan et al. [15], in which prior hydrolysis resulted in higher xylitol concentration and productivity.

The overall processing time could be further improved by increasing the initial biomass concentration for the fermentation, or in other words increasing the inoculum size added to the system (Fig $\mathbf{6 b}-\mathbf{c})$. Table 2 shows the effects of initial cell concentrations on cell and xylitol productivities. In addition, the increase in the initial cell concentrations shortened the total processing time despite of longer prior hydrolysis time. These results showed that the fermentation process was the limiting factor of xylitol production. Increasing concentration of cell inoculum is thus recommended to increase xylitol productivity and shorten the total process time.

\section{Comparison of configurations of all processes}

Various process configurations for xylitol production have been simulated. We summarized the effect of process configuration and process temperature to overall processing time, cell and xylitol productivities at the same initial xylan and cell concentration $(100 \mathrm{~g} / \mathrm{L}$ and $0.5 \mathrm{~g} / \mathrm{L})$. The summary of cell and xylitol productivity and the time required to achieve the maximum xylitol concentration are shown in Table 3. SSF at optimum condition temperature provided better cell and xylitol productivities than SSF at the optimum fermentation temperature. SSF with high initial cell concentration increased the cell and xylitol productivities further. The best SSF configuration obtained in the simulations, that was 21 hours prior hydrolysis at the optimum hydrolysis temperature followed by SSF at $36^{\circ} \mathrm{C}$ by adding cell inoculum up to $2 \mathrm{~g} / \mathrm{L}$, shortened the overall processing time to achieve the maximum xylitol concentration to 77 hours, or $39.84 \%$, when compared with the SHF. The overall processing time for SHF was 128 hours whereas the overall processing time for the best SSF configuration was 77 hours. 
1 The obtained results confirmed previous results of Burhan et al. [19] and Öhgren et al. [42] which produced xylitol

2 and ethanol using the SHF and SSF methods and obtained higher productivity results when using the SSF

3 configuration.

4 The results of SSF simulation showed that the optimum temperature, intermediate xylose formation-reduction,

5 xylitol formed, and biomass growth could be predicted adequately. Experimental validation through testing the

6 SSF temperature and the pre-hydrolysis time could be conducted further to confirm the accuracy of model

7 parameters that were used.

8 Overall, simulation of the developed kinetic model has been applied to design the configuration and the 9 operational of SSF process. The model could be further improved by the incorporation of non-ideal conditions such as the inhibitory term to the hydrolysis process [43] or the inhibitory term to xylitol fermentation process [7,

$1144,45]$ to give a more accurate estimation of the SSF process of lignocellulosic material. Details kinetics of the related process as well as the estimated concentration of inhibitory substance in a specific process, for example SSF of OPEFB, needed to be defined. Nonetheless, this paper showed that SSF or semi SSF is an alternative process configuration that led to higher product (xylitol) productivity.

\section{Concluding Remarks}

17 The kinetic model describing the SSF for xylitol production from hemicellulose of lignocellulosic material has been successfully developed and simulated. Our simulation showed that the performance of SSF process was affected by the process temperature, the length of prior hydrolysis or the switching time, and the biomass initial concentration. Overall, it was concluded that the SSF configuration led to higher xylitol productivity than the SHF. The best SSF configuration was combination of prior hydrolysis at the optimum hydrolysis temperature for 21 hour (semi SSF), SSF temperature of $36^{\circ} \mathrm{C}$, and initial biomass concentration of $2 \mathrm{~g} / \mathrm{L}$, which the led to an increase cell and xylitol productivity to 0.307 and $0.599 \mathrm{~g} /(\mathrm{L} . \mathrm{h})$, respectively.

\section{Declarations}

Ethics approval and consent to participate

Not applicable

\section{Consent for publication}


1 All authors confirm and consent to publish this manuscript.

2

3 Availability of data and materials

4 The simulation data that support the findings of this study are available from the corresponding author upon

5 reasonable request.

6

7 Competing interest

8 The authors declare that they have no conflict of interest.

9

10 Funding

11 This research was funded by the Ministry of Research and Technology (Kemenristekdiki) Republik Indonesia

12 under the Program Magister Doktor untuk Sarjana Unggul (PMDSU) (grant numbers 0017y/I1.C06/PL/2019).

\section{Authors' contributions}

IMH: Conceptualization, Data acquisition, Formal analysis, Investigation, Visualization, Writing-original draft,

Writing-review and editing; TS: Conceptualization, Funding acquisition, Methodology, Project administration, Supervision; MTAPK: Conceptualization, Formal analysis, Methodology, Project administration, Supervision, Visualization, Writing-original draft, Writing-review and editing.

\section{Acknowledgments}

21 We would like to acknowledge the Ministry of Research and Technology (Kemenristekdiki) Republik Indonesia under the Program Magister Doktor untuk Sarjana Unggul (PMDSU) for research funding support (grant numbers 0017y/I1.C06/PL/2019). Also, we would like to thank Aulia Maulana for assisting in the model and simulation.

\section{Authors' information}

${ }^{1}$ Department of Chemical Engineering, Faculty of Industrial Technology, Institut Teknologi Bandung, Jalan Ganesha No. 10, Bandung, West Java, Indonesia, 40132. ${ }^{2}$ Department of Food Engineering, Faculty of Industrial Technology, Institut Teknologi Bandung, Kampus Jatinangor, Sumedang, Indonesia. 


\section{References}

2 1. Nayak PA, Nayak UA, Khandelwal V (2014) The effect of xylitol on dental caries and oral flora. Clin Cosmet Investig Dent 6:89-94. https://doi.org/10.2147/CCIDE.S55761

2. Mäkinen KK (2010) Sugar Alcohols, Caries Incidence, and Remineralization of Caries Lesions: A Literature Review. Int J Dent 2010:1-23. https://doi.org/10.1155/2010/981072

6 3. Ramesh S, Muthuvelayudham R, Rajesh Kannan R, Viruthagiri T (2013) Enhanced production of xylitol from corncob by Pachysolen tannophilus using response surface methodology. Int J Food Sci 2013:. https://doi.org/10.1155/2013/514676

9 4. Granstrom TB (2002) Biotechnological production of xylitol with Candida yeasts

5. Aranda-Barradas JS, Garibay-Orijel C, Badillo-Corona JA, Salgado-Manjarrez E (2010) A stoichiometric analysis of biological xylitol production. Biochem Eng J 50:1-9. https://doi.org/10.1016/j.bej.2009.10.023

6. Ur-Rehman S, Mushtaq Z, Zahoor T, et al (2015) Xylitol: A Review on Bioproduction, Application, Health Benefits, and Related Safety Issues. Crit Rev Food Sci Nutr 55:1514-1528. https://doi.org/10.1080/10408398.2012.702288 production and key enzyme activities by a xylose utilizing yeast Candida athensensis SB18. Bioresour Technol 121:369-378. https://doi.org/10.1016/j.biortech.2012.07.020

8. Anil N, Sudarshan K, Naidu NN, Ahmed M (2016) Production of Xylose from Corncobs. Int J Eng Res Appl 6:77-84

9. Cortez DV, Roberto IC (2010) Improved xylitol production in media containing phenolic aldehydes: Application of response surfacemethodology for optimization and modeling of bioprocess. J Chem

10. Sun J, Liu H (2011) Selective hydrogenolysis of biomass-derived xylitol to ethylene glycol and propylene glycol on supported Ru catalysts. Green Chem 13:135-142. https://doi.org/10.1039/c0gc00571a

11. Huang Z, Chen J, Jia Y, et al (2014) Selective hydrogenolysis of xylitol to ethylene glycol and propylene glycol over copper catalysts. Appl Catal B Environ 147:377-386. https://doi.org/10.1016/j.apcatb.2013.09.014

12. Gowda JI, Nandibewoor ST (2012) Mechanism of oxidation of xylitol by a new oxidant, 
diperiodatoargentate (III), in aqueous alkaline medium. Synth React Inorganic, Met Nano-Metal Chem 42:1183-1191. https://doi.org/10.1080/15533174.2012.684261

13. Srivastava A, Bansal S (2015) Kinetics and Mechanism of Ru ( III ) Catalysed Oxidation of Xylitol by Chloramine-T in Perchloric Acid Medium. 4:39-48

14. Baudel HM, de Abreu CAM, Zaror CZ (2005) Xylitol production via catalytic hydrogenation of sugarcane bagasse dissolving pulp liquid effluents over Ru/C catalyst. J Chem Technol Biotechnol 80:230-233. https://doi.org/10.1002/jctb.1155

15. Delgado Arcaño Y, Valmaña García OD, Mandelli D, et al (2020) Xylitol: A review on the progress and challenges of its production by chemical route. Catal Today 344:2-14. https://doi.org/10.1016/j.cattod.2018.07.060

16. Rafiqul ISM, Sakinah AMM (2013) Processes for the Production of Xylitol-A Review. Food Rev Int 29:127-156. https://doi.org/10.1080/87559129.2012.714434

17. Dasgupta D, Bandhu S, Adhikari DK, Ghosh D (2017) Challenges and prospects of xylitol production with whole cell bio-catalysis: A review. Microbiol Res 197:9-21. https://doi.org/10.1016/j.micres.2016.12.012

18. Kresnowati M, Mardawati E, Setiadi T (2015) Production of Xylitol from Oil Palm Empty Friuts Bunch: A Case Study on Bioefinery Concept. Mod Appl Sci 9:206. https://doi.org/10.5539/mas.v9n7p206

19. Burhan KH, Kresnowati MTAP, Setiadi T (2019) Evaluation of simultaneous saccharification and fermentation of oil palm empty fruit bunches for xylitol production. Bull Chem React Eng \&amp;amp; Catal 14:559-567. https://doi.org/10.9767/bcrec.14.3.3754.559-567

20. Wyman CE, Spindler DD, Grohmann K (1992) Simultaneous saccharification and fermentation of several lignocellulosic feedstocks to fuel ethanol. Biomass and Bioenergy 3:301-307. https://doi.org/10.1016/0961-9534(92)90001-7

21. F Alfani, A Gallifuoco, A Saporosi AS and MC (2002) Comparison of SHF and SSF processes for the bioconversion of steam-exploded wheat straw. 123:71-75

22. Ballesteros M, Oliva JM, Negro MJ, et al (2004) Ethanol from lignocellulosic materials by a simultaneous saccharification and fermentation process (SFS) with Kluyveromyces marxianus CECT 10875. Process Biochem 39:1843-1848. https://doi.org/10.1016/j.procbio.2003.09.011

23. Tomás-Pejó E, Oliva JM, Ballesteros M, Olsson L (2008) Comparison of SHF and SSF processes from 
steam-exploded wheat straw for ethanol production by xylose-fermenting and robust glucose-fermenting Saccharomyces cerevisiae strains. Biotechnol Bioeng 100:1122-1131. https://doi.org/10.1002/bit.21849

24. Shen J, Agblevor FA (2010) Modeling semi-simultaneous saccharification and fermentation of ethanol production from cellulose. Biomass and Bioenergy 34:1098-1107. https://doi.org/10.1016/j.biombioe.2010.02.014

25. Gonçalves FA, Ruiz HA, Nogueira CDC, et al (2014) Comparison of delignified coconuts waste and cactus for fuel-ethanol production by the simultaneous and semi-simultaneous saccharification and fermentation strategies. Fuel 131:66-76. https://doi.org/10.1016/j.fuel.2014.04.021

26. Mardawati E, Werner A, Bley T, et al (2014) The Enzymatic Hydrolysis of Oil Palm Empty Fruit Bunches to Xylose. J Japan Inst Energy 93:973-978. https://doi.org/10.3775/jie.93.973

27. Meilany D, Mardawati E, Tri M, et al (2017) Kinetic Study of Oil Palm Empty Fruit Bunch Enzymatic Hydrolysis. 17:197-202

28. Sampaio FC, De Moraes CA, De Faveri D, et al (2006) Influence of temperature and pH on xylitol production from xylose by Debaryomyces hansenii UFV-170. Process Biochem 41:675-681. https://doi.org/10.1016/j.procbio.2005.08.019

29. Sánchez S, Bravo V, Moya AJ, et al (2004) Influence of temperature on the fermentation of D-xylose by Pachysolen tannophilus to produce ethanol and xylitol. Process Biochem 39:673-679. https://doi.org/10.1016/S0032-9592(03)00139-0

30. Gummadi SN, Kumar S (2008) Effects of temperature and salts on growth of halotolerant Debaryomyces nepalensis NCYC 3413. Am. J. Food Technol. 3:354-360

31. Mohamad NL, Mustapa Kamal SM, Gliew A (2009) Effects of temperature and pH on xylitol recovery from oil palm empty fruit bunch hydrolysate by Candida tropicalis. J. Appl. Sci. 9:3192-3195

32. Michael L. Shuler; Fikret Kargi (2002) Bioprocess Engineering Basic Concepts, Second. Prentice hall PTR, New Jersey (NJ)

33. John Villadsen;Jens Nielsen;Gunnar Liden (2011) Bioreaction Engineering Principles, Third. Springer, New York

34. Mardawati E, Trirakhmadi A, Kresnowati M, Setiadi T (2017) Kinetic study on Fermentation of xylose for The Xylitol Production. J Ind Inf Technol Agric 1:1. https://doi.org/10.24198/jiita.v1i1.12214

35. Josefa K. M, Alejandro B, Juan P. A, et al (2018) Biotechnological Production of Xylitol from Oil Palm Empty Fruit Bunches Hydrolysate. Adv J Food Sci Technol 16:134-137. 
https://doi.org/10.19026/ajfst.16.5945

36. Zhou J, Liu Y, Shen J, et al (2015) Kinetic and thermodynamic characterization of a novel lowtemperature-active xylanase from Arthrobacter sp. GN16 isolated from the feces of Grus nigricollis. Bioengineered 6:111-114. https://doi.org/10.1080/21655979.2014.1004021

37. Pappu JSM, Gummadi SN (2016) Modeling and simulation of xylitol production in bioreactor by Debaryomyces nepalensis NCYC 3413 using unstructured and artificial neural network models. Bioresour Technol 220:490-499. https://doi.org/10.1016/j.biortech.2016.08.097

38. Dominguez J. M. Cheng S. G. 2 and Tsao G. T. (1997) Production of xylitol from D-xylose by debaryomyces hansenii. Appl Biochem Biotechnol - Part A Enzym Eng Biotechnol 63-65:117-127. https://doi.org/10.1007/BF02920418

39. Breuer U, Harms H (2006) Debaryomyces hansenii - An extremophilic yeast with biotechnological potential. Yeast 23:415-437. https://doi.org/10.1002/yea.1374

40. Converti A, Perego P, Domínguez JM, Silva SS (2001) Effect of temperature on the microaerophilic metabolism of Pachysolen tannophilus. Enzyme Microb Technol 28:339-345. https://doi.org/10.1016/S0141-0229(00)00330-6

41. Bajpai P (2014) Chapter 2 - Xylan: Occurrence and Structure. In: Bajpai P (ed) Xylanolytic Enzymes. Academic Press, Amsterdam, pp 9-18

42. Öhgren K, Bura R, Lesnicki G, et al (2007) A comparison between simultaneous saccharification and fermentation and separate hydrolysis and fermentation using steam-pretreated corn stover. Process Biochem 42:834-839. https://doi.org/10.1016/j.procbio.2007.02.003

43. Maulana Hidayatullah I, Setiadi T, Tri Ari Penia Kresnowati M, Boopathy R (2020) Xylanase inhibition by the derivatives of lignocellulosic material. Bioresour Technol 300:122740. https://doi.org/10.1016/j.biortech.2020.122740

44. Wannawilai S, Chisti Y, Sirisansaneeyakul S (2017) A model of furfural-inhibited growth and xylitol production by Candida magnoliae TISTR 5663. Food Bioprod Process 105:129-140. https://doi.org/10.1016/j.fbp.2017.07.002

45. Sampaio FC, Torre P, Passos FML, et al (2007) Influence of inhibitory compounds and minor sugars on xylitol production by Debaryomyces hansenii. Appl Biochem Biotechnol 136:165-181. https://doi.org/10.1007/BF02686021 


\section{Figure Captions}

2 Fig 1. Bioprocess-based xylitol production

3 Fig 2. Effect of temperature on hydrolysis and fermentation processes; the blue line (-) denotes the

4 fermentation model; the red line $(-)$ represents the hydrolysis model

5 Fig 3. Xylitol production by using the SHF method, both the hydroylysis and the succeeding fermentation were

6 conducted at their optimum temperatures

$7 \quad$ Fig 4. Xylitol production via SSF method conducted at (a) the optimum hydrolysis temperature and (b) the

8 optimum fermentation temperature

$9 \quad$ Fig 5. The results of SSF simulation for contour map showing temperature, process time, and xylitol

10 productivity

11 Fig 6. Contour map showing the effect of switching time to xylitol concentration at initial cell concentration of (a) $0.5 \mathrm{~g} / \mathrm{L}$; (b) $1 \mathrm{~g} / \mathrm{L}$; and (c) $2 \mathrm{~g} / \mathrm{L}$.

14 Table Captions

15 Table 1. Supporting data for modeling and simulation of xylitol production

16 Table 2. The effect of initial cell concentration in the inoculum to SSF for xylitol production

17 Table 3. Results of all configurations of processes of xylitol production 
Figures

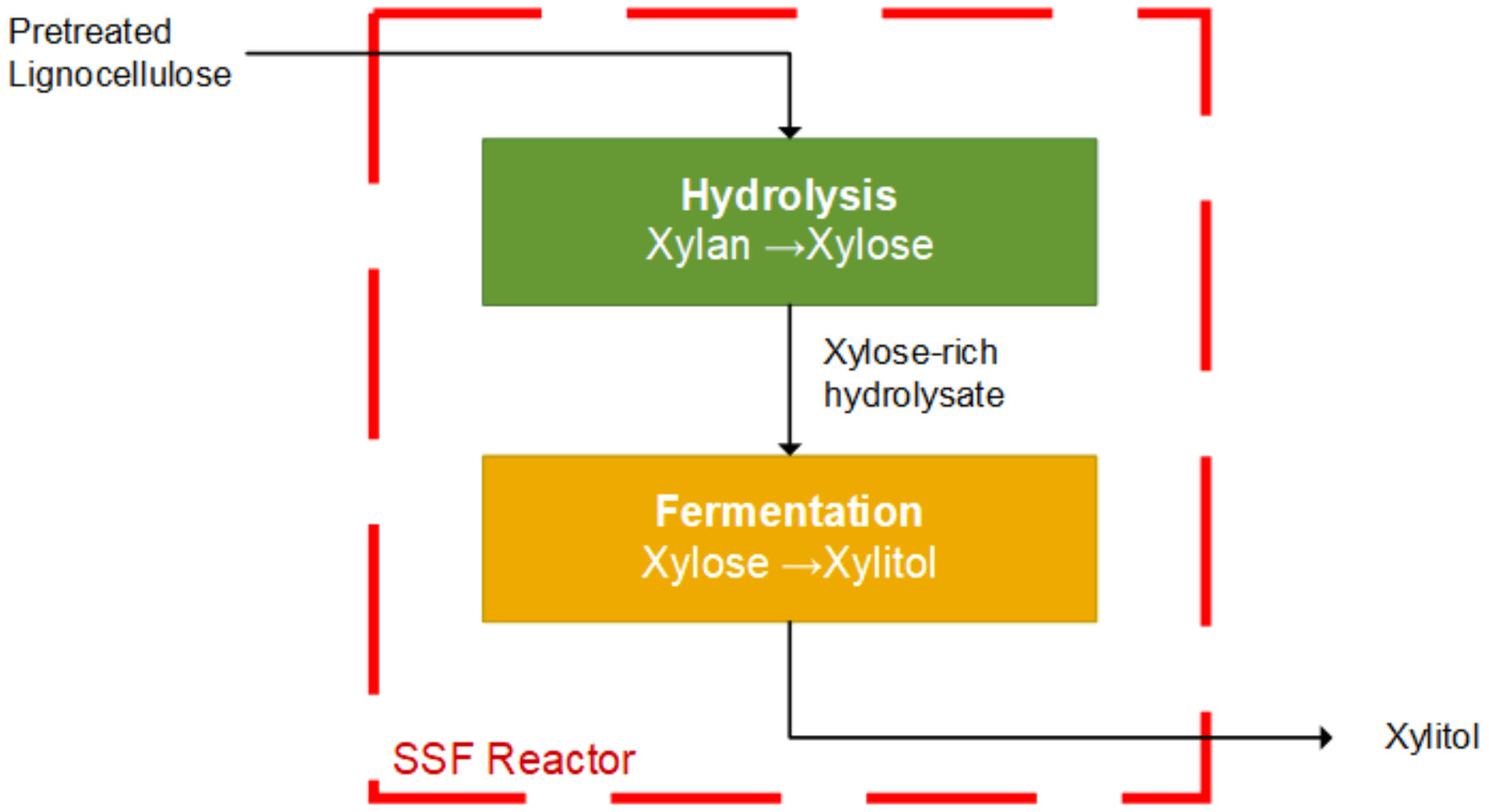

Figure 1

Bioprocess-based xylitol production 


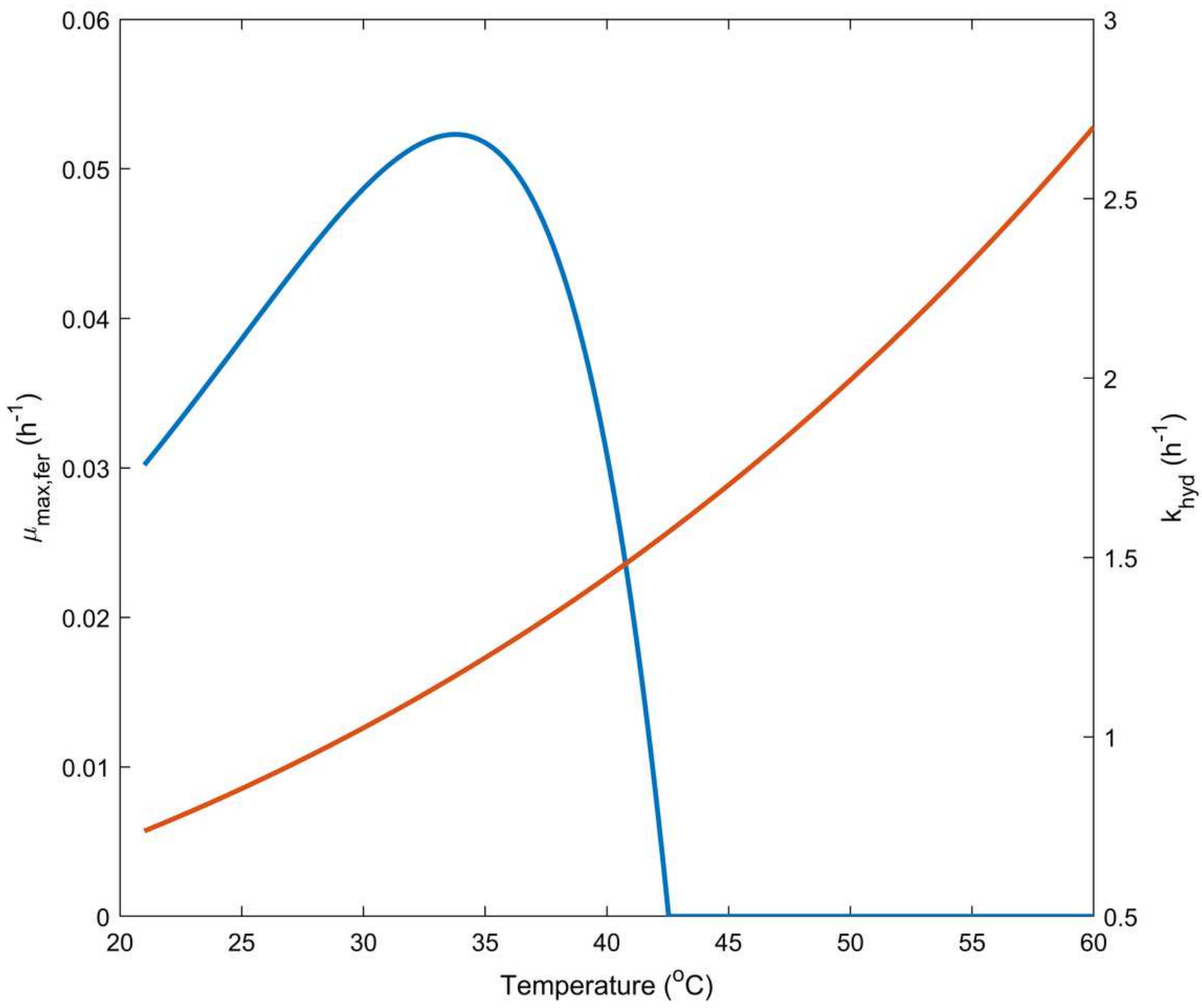

Figure 2

Effect of temperature on hydrolysis and fermentation processes; the blue line (-) denotes the fermentation model; the red line $(-)$ represents the hydrolysis model 


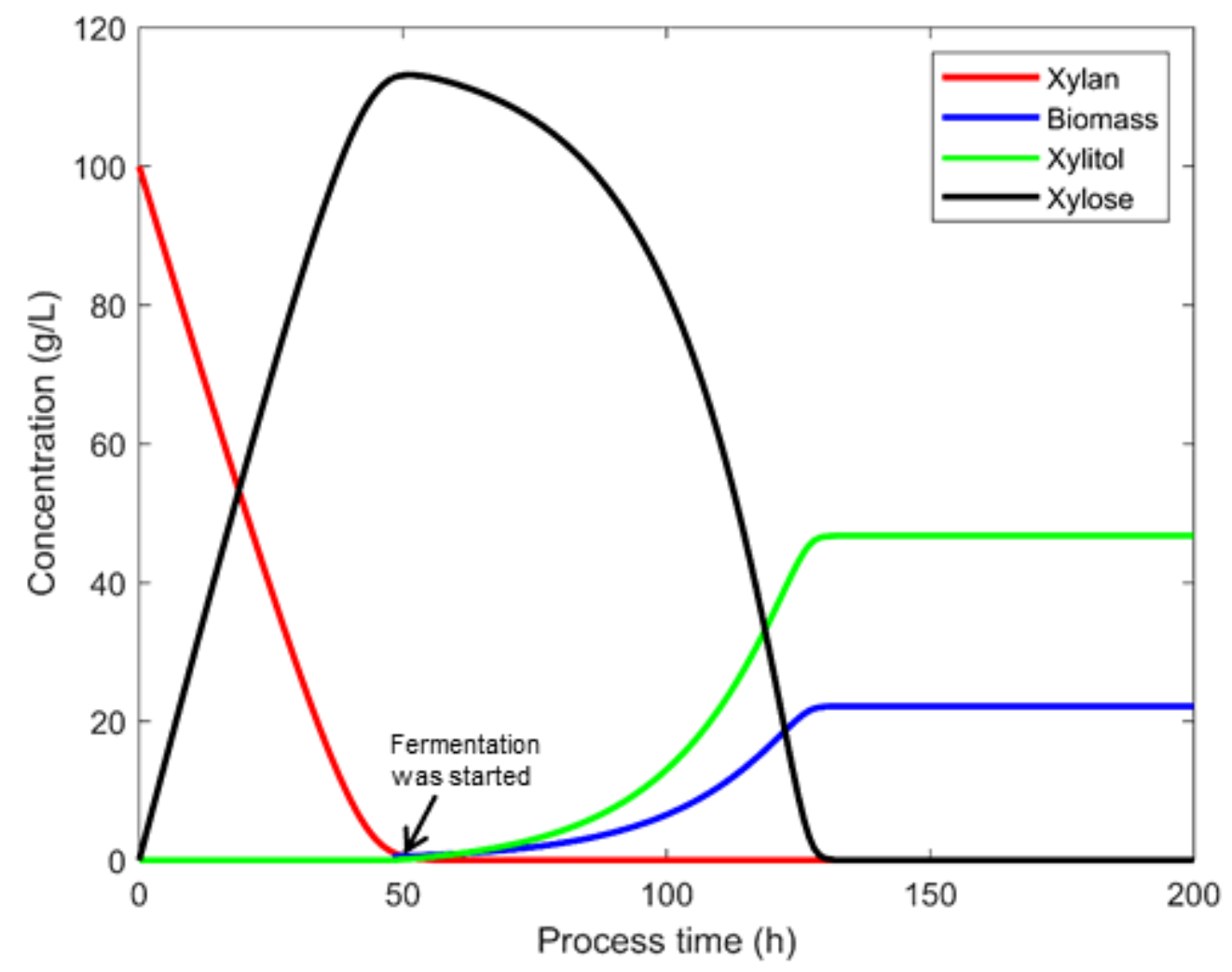

Figure 3

Xylitol production by using the SHF method, both the hydroylysis and the succeeding fermentation were conducted at their optimum temperatures
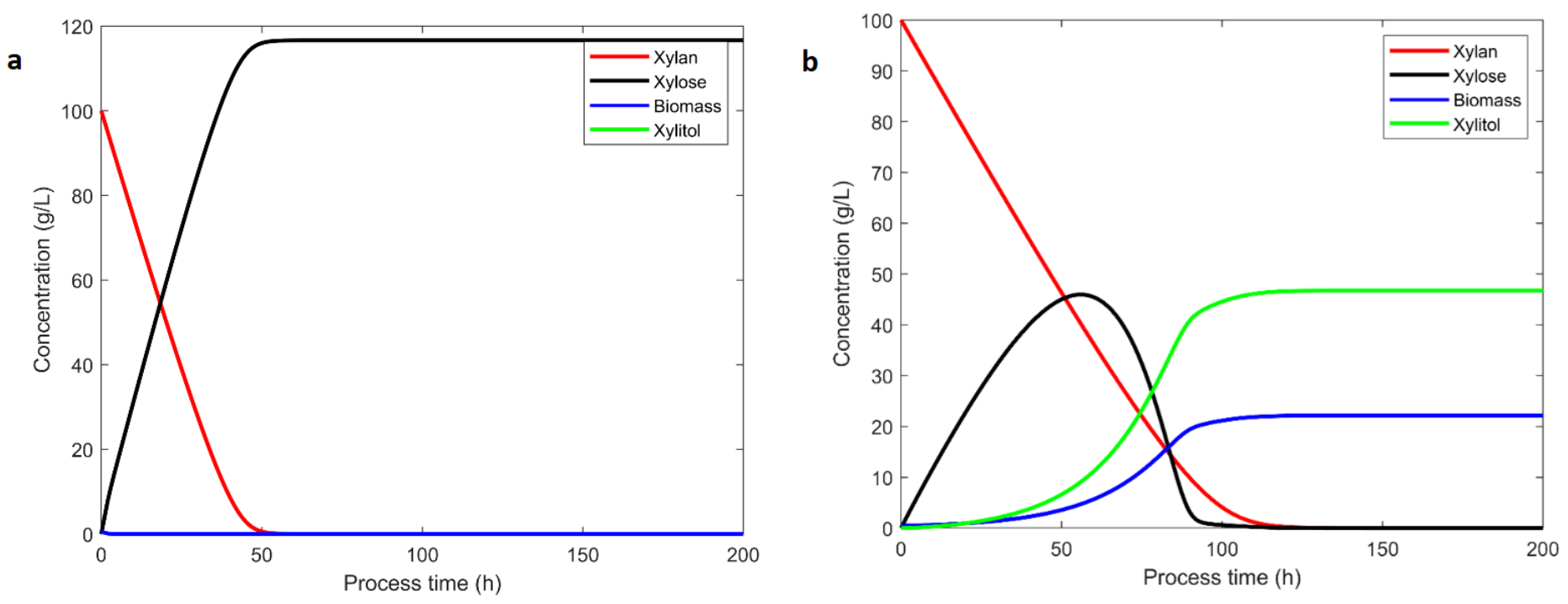

Figure 4

Xylitol production via SSF method conducted at (a) the optimum hydrolysis temperature and (b) the optimum fermentation temperature 


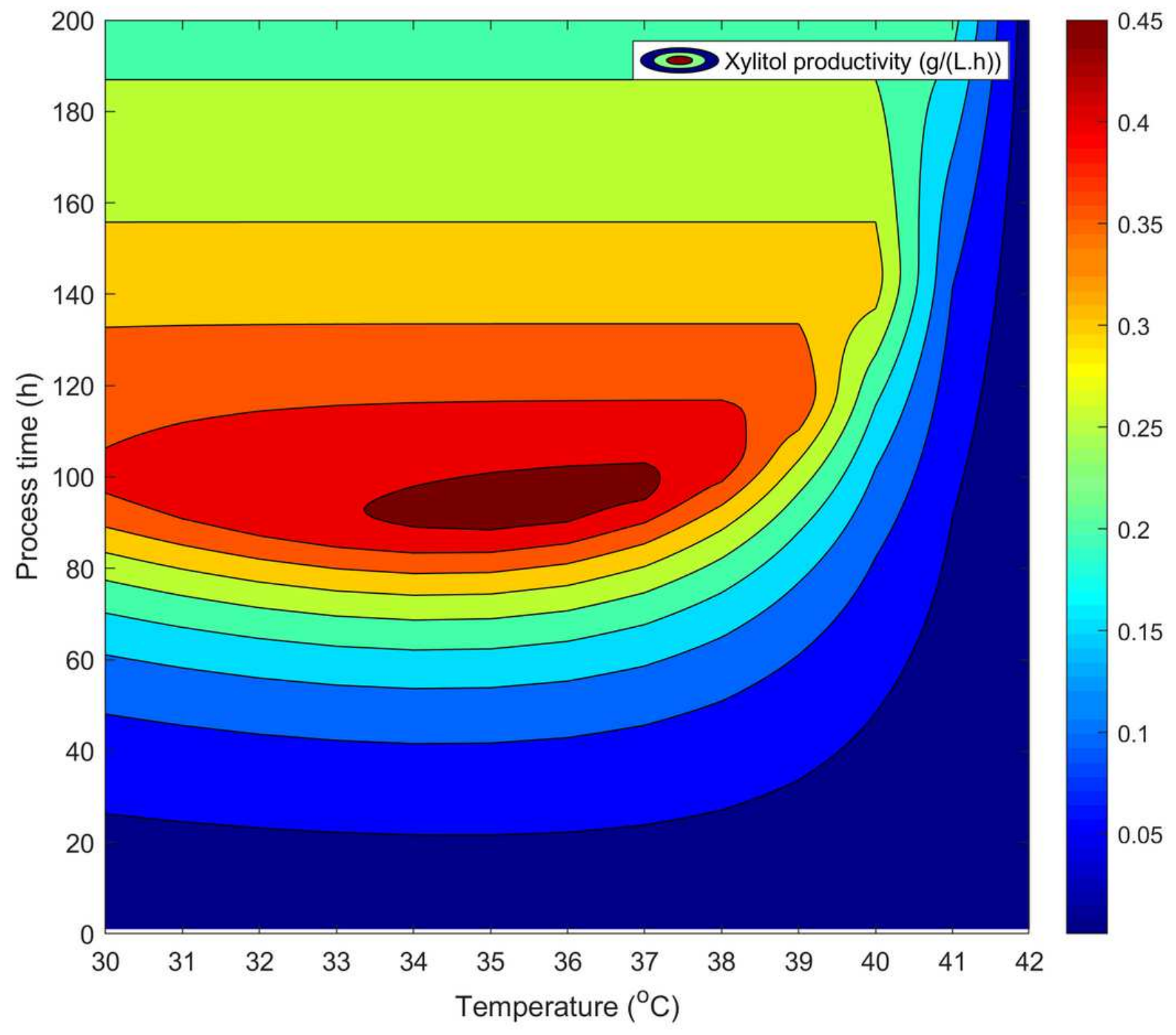

\section{Figure 5}

The results of SSF simulation for contour map showing temperature, process time, and xylitol productivity
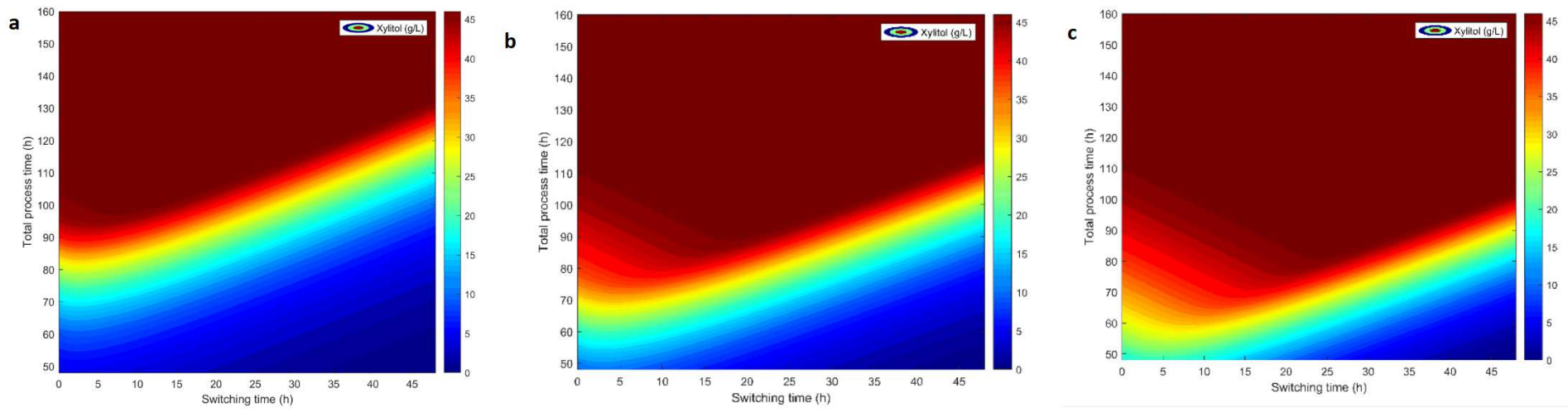
Figure 6

Contour map showing the effect of switching time to xylitol concentration at initial cell concentration of (a) $0.5 \mathrm{~g} / \mathrm{L}$; (b) $1 \mathrm{~g} / \mathrm{L}$; and (c) $2 \mathrm{~g} / \mathrm{L}$.

\section{Supplementary Files}

This is a list of supplementary files associated with this preprint. Click to download.

- GraphicalAbstractSSF.png 